\title{
On Engagement With ICT Standards and Their Implementations in Open Source Software Projects:
}

\section{Experiences and Insights From the Multimedia Field}

\author{
Jonas Gamalielsson, University of Skövde, Sweden \\ Björn Lundell, University of Skövde, Sweden
}

\begin{abstract}
The overarching goal in this paper is to investigate organisational engagement with an ICT standard and open source software (OSS) projects that implement the standard, with a specific focus on the multimedia field, which is relevant in light of the wide deployment of standards and different legal challenges in this field. The first part reports on experiences and insights from engagement with standards in the multimedia field and from implementation of such standards in OSS projects. The second part focuses on the case of the ITU-T H.264 standard and the two OSS projects OpenH264 and $\times 264$ that implement the standard, and reports on a characterisation of organisations that engage with and control the H.264 standard, and organisations that engage with and control OSS projects implementing the H.264 standard. Further, projects for standardisation and implementation of H.264 are contrasted with respect to mix of contributing organisations, and findings are related to organisational strategies of contributing organisations and previous research.
\end{abstract}

\section{KEYWORDS}

AVC, H.264, Involvement, ISO, ITU-T, OpenH264, Participation, x264

\section{INTRODUCTION}

There are a number of different challenges related to provision of standards in the software sector, that can impact on the extent to which it is possible to faithfully implement the specification of a standard in software systems (Blind and Böhm, 2019; Gamalielsson and Lundell, 2013; Lundell et al., 2019; UK, 2015). A number of challenges that are related to implementation of specifications of standards have been identified in the literature, including challenges related to: interoperability (Bird, 1998; Ghosh, 2005; Krechmer, 2005), conformance to the specification of the standard (Egyedi, 2007; Lundell et al., 2019), and long term availability of software systems which implement specific standards and associated digital artefacts (Behlendorf, 2009; Lundell et al., 2011). Implementations of standards in Open Source Software (OSS) is one means to address these challenges, and such implementations need to be available over very long life-cycles. For this reason it is important to assess the longevity of organisational governance and development provided by organisations in standardisation- and OSS projects (Butler et al., 2020; Crowston and Howison, 2006). Organisational engagement with standardisation projects is an important aspect to consider in this regard, and there is previous

\section{DOI: 10.4018/IJSR.287102}

This article published as an Open Access article distributed under the terms of the Creative Commons Attribution License (http://creativecommons.org/licenses/by/4.0/) which permits unrestricted use, distribution, and production in any medium, provided the author of the original work and original publication source are properly credited. 
research on this topic including studies with a focus on motives for organisational participation in standardisation (Blind, 2006; Blind and Mangelsdorf, 2016; Mangelsdorf, 2009; Riillo, 2013), and how participation in standardisation affects company performance (Wakke et al., 2016).

Previous research on standards and their implementations in software projects include studies the addressing of different aspects related to interoperability and compliance (e.g. Butler et al., 2020; Egyedi, 2007; Egyedi and Dahanayake, 2003; Friedrich, 2011), and aspects that relate to licensing conditions for standards and associated implementations in OSS (Friedrich, 2011; Ghosh, 2005; Lundell et al., 2019; Simcoe, 2006). In particular, the relationship between standards and their implementations in software is a contemporary concern that has been addressed in a number of different studies (Blind and Böhm, 2019; Egyedi and van Wendel de Joode, 2004; Lundell et al., 2019). However, there is a lack of case studies, especially with a focus on standards and their software implementations in the multimedia domain, which is of interest because of their wide deployment and associated legal challenges. Therefore, there is need for further research with a focus on specific implementations of standards and the engagement with standards and their associated implementations, and particularly related to implementations in OSS in the multimedia field. In fact, the openness of standards and associated implementations in OSS has been elaborated almost two decades ago (Krechmer, 2002) and the relationship between standards and their implementation in OSS continues to be an issue for ongoing discussion (Brock, 2013; Blind and Böhm, 2019; EU, 2012; FRAND, 2012; Friedrich, 2011, 2013; Krechmer, 2007; Lundell et al., 2019). Further, there is a practical relevance of research on standards and their software implementations in the multimedia field since a large proportion of ICT users consume multimedia content through broadcasting and streaming services, and are depending on and affected by those standards and implementations.

This research addresses ICT standards which can be implemented in software projects, and considers challenges and opportunities concerning their implementation in OSS projects. Software that complies with the Open Source Definition (OSI, 2020b) and is made available under a software licence which has been approved by the Open Source Initiative (OSI, 2020a) constitutes OSS. Specifically, we address standards in the multimedia field and in particular the H.264 standard that has been jointly standardised by the International Telecommunication Union - Telecommunication Standardization Sector (ITU-T) and the International Organization for Standardization (ISO) ${ }^{1}$, and investigate engagement with the ITU-T H.264 standard (hereafter referred to as H.264) and selected OSS implementations of the standard.

One reason for the choice to investigate standards in the multimedia field and H.264 in particular, is that the standard is widely deployed, especially in the context of online streaming of video content: "H.264/AVC continues to be a pillar of online streaming, taking the top spot three years in a row, as the most used video codec in 2019 at 91\%" (Bitmovin, 2019). For example, the standard is used in different software implementations in public broadcasting scenarios, including in the context of the Swedish public broadcasting organisation SVT, where high definition transmissions exclusively rely on use of the H.264 standard (SVT, 2020). Further, the implementation of multimedia standards and particularly H.264 is known to be challenging from a legal perspective. For example, a large number of organisations hold standard essential patents (SEPs) for H.264 of which a subset of organisations provide licences for their SEPs through the MPEG LA patent pool (MPEGLA, 2019). Hence, since H.264 is not royalty free, it does not fulfil requirements for an open standard according to the European Interoperability Framework version 1.0 (EU, 2004). Despite that H.264 is not an open standard, there are numerous implementations of H.264 in software provided under different licences (including proprietary licences and OSS licences).

This paper contributes the first in-depth study on organisational engagement with multimedia standards and OSS implementation of such standards, and also with a more specific focus on the H.264 standard and OSS implementations of that standard. The overarching goal for this study is to investigate organisational engagement with an ICT standard and OSS projects that implement the standard. The study has two parts. In the first part, four research questions are addressed in 
the context of standards in the multimedia domain and implementation of such standards in OSS projects. $\boldsymbol{R Q 1}$ : Why do individuals and organisations get engaged with governance and development of standards for multimedia formats?; $\boldsymbol{R} \boldsymbol{Q} 2$ : Why do individuals and organisations get engaged with standard implementations for multimedia formats in open source software projects?; $\boldsymbol{R} \boldsymbol{Q} 3$ : What are the challenges for individuals and organisations to get engaged with governance and development of standards for multimedia formats?; $\boldsymbol{R} \mathbf{Q}$ : What are the challenges for individuals and organisations to get engaged with standard implementations for multimedia formats in open source software projects? The two research questions RQ1 and RQ2 are motivated by that they explore two different and complementary standardisation contexts (governance \& development of standards, and standard implementations) that together are important to advance standardisation, especially in the field of multimedia. Similarly, addressing RQ3 and RQ4 contributes to the understanding of contemporary (and future) challenges for the two contexts in the field of multimedia.

In the second part, two research questions are addressed in the specific case of the H.264 standard (ITU-T, 2019) and the two OSS projects OpenH264 (openh264.org, 2020) and x264 (videolan.org, 2020a) that implement the standard. RQ5: What characterises organisations that engage with and control the H.264 standard?; RQ6: What characterises organisations that engage with and control OSS projects implementing the H.264 standard? RQ5 and RQ6 complement the research questions in first part of the study by exploring and presenting specific details concerning engagement with a widely deployed, and patent encumbered, ICT standard in the multimedia field and associated OSS implementations.

\section{BACKGROUND}

The meaning of 'standards' and how businesses may benefit from using standards in various contexts have been a topic for discussion in the field of ICT since the 1990s (e.g. Bird, 1998). Standards can be attributed the function of creating norms and can thereby "establish requirements that, though not expressed in formal legal instruments, are in practice mandatory and must be implemented by participants in certain fields of technical or business activity" (Fitzgerald \& Pappalardo, 2009). Formal standards are provided by different organisations that are recognised as formal standardisation organisations (de Vries, 2006). Examples of such organisations are ISO, ITU (International Telecommunication Union), ETSI (European Telecommunication Standards Institute), and national standardisation organisations (e.g. British Standards Institute). Industry consortia and other bodies (e.g. W3C (World Wide Web Consortium) that are not formal standardisation organisations also create standards that are subject to de facto adoption in industry. Such an informal standard may be submitted to a formal standardisation organisation in order to become accepted as a formal standard through adoption by the formal standardisation organisation. Engagement with and participation in standardisation has been explored in a number of research studies. For example, the impact of participation within formal standardisation on the performance of firms has been investigated in the German context (Wakke et al., 2016). Further, motivations amongst organisations for participating in standardisation have been investigated. One study explored explanatory factors for company participation in formal standardisation processes in the German context (Blind, 2006). Similarly, driving factors of service companies to participate in formal standardisation processes have been investigated and tested (Mangelsdorf, 2009). Further, different strategic motives were identified for German manufacturing companies in the electrical engineering and machinery industry to be involved in standards development organisations (Blind and Mangelsdorf, 2016). A different study explored characteristics and motivations of participants from Luxembourg in national and international formal standardization activities (Riillo, 2013). The the role of individuals participating in standards setting has been investigated in the context of POSIX standardisation (Isaak, 2006). Another example is a study that explored organisational involvement and collaboration in W3C standards through editorship (Gamalielsson and Lundell, 2017b). 
The ICT standard H.264 and its use is complicated from a legal perspective. One reason being that more than 55 organisations (of which a clear majority are larger enterprises in the ICT field) have filed patent declarations involving a large number of patents for H.264 at ITU-T (ITU-T, 2020c). A subset of these organisations license their SEPs through the MPEG LA patent pool (MPEGLA, 2019). Hence, implementation of the standard in software involves royalty fees, which may inhibit use of the standard and inhibit interoperability. An example initiative aiming to promote interoperability and mitigate issues related to SEPs is the OpenH264 OSS project, where the maintainer Cisco provides binary modules implementing the standard for inclusion in other software without the need for users to acquire their own patent licences, since Cisco covers licensing costs to MPEG-LA (Mozilla, 2013; openh264.org, 2020). Further, a different challenge is for small organisations to contribute to multimedia standardisation processes (such as H.264) in the context of formal standardisation organisations (including ITU-T). Specifically, the fees for participation and cost for representatives from small companies to attend international meetings in standardisation projects may be prohibitive (Blind and Böhm, 2019; Krechmer, 2006; Lundell et al., 2015).

Over the years, the H.264 standard has been implemented in a number of different software systems provided by numerous different organisations (including large global enterprises, such as Cisco) and OSS projects (including OpenH264 and x264). An characteristic inherent to OSS is that adopters of such software have the right to freely read, use, improve, and re-distribute the source code. Over the last decades, many professionals and volunteers with strong community values inherent to OSS cultures have contributed to many OSS projects in different contexts. Such software is used in many contexts both in the private and public sector (Brock, 2013; Butler et al., 2020; Fitzgerald, 2006; Lundell and van der Linden, 2013).

Many different licences exist under which OSS can be provided (Bain, 2012; Brock, 2013; Engelfriet, 2010; Rosen, 2004), and licences are often broadly categorised as either 1) copyleft licences (e.g. GPL and LGPL) or 2) permissive licences (e.g. BSD and MIT). The main difference between these two licence categories is that copyleft licences ensure that derivative work remains OSS, whereas permissive licences do not (Brock, 2013). The GPL licence, that has an origin in the free software movement (FSF, 2020), is recognised by OSI (2020) and this licence has been broadly used by many OSS projects, including projects that have attracted a significant amount of commercial interest (Fitzgerald, 2006; Lundell and van der Linden, 2013). In addition to the OSS licence GPL (used by several well known projects, including the Linux kernel project which is licensed under GPL version 2), there are also other copyleft licences in the GPL family (AGPL and LGPL) recognised by OSI (Bain, 2012; Brock, 2013; Engelfriet, 2010; Rosen, 2004). Further, it has been shown that $60 \%$ of 200 widely used OSS projects are provided under the GPL-family of licences (Gamalielsson and Lundell, 2017a).

For widely deployed implementations of the H.264 standard, we note that copyleft licences have been used for OSS implementations of the standard (e.g. x264, released under GPL v2), and also permissive licences (e.g. OpenH264, released under a BSD 2-clause licence). Further, ITU-T provides reference software for H.264 that is maintained by Fraunhofer HHI (Heinrich Hertz Institute) under permissive conditions (ITU-T, 2016).

An inherent characteristic of OSS projects is that such promote an open collaboration between individuals representing companies and other types of organisations. With the inherent transparency stemming from the open collaboration in OSS projects, important details concerning the precise interpretation of a specification of a standard becomes transparent when implemented in OSS. OSS projects can thereby aid in promoting faithful interpretations of specifications of standards and thereby constitute a valuable additional resource for the ongoing development and maintenance of standards. From this, the quality of specifications of standards in the software domain can improve over time. In fact, a number of standards have been implemented in various OSS projects, and sometimes such implementations have even been instrumental in promoting the standard itself (Behlendorf, 2009; Blind and Böhm, 2019). 
The relationship between ICT standards and their implementations in OSS is complex and has been a long-term concern that has been addressed in a number of studies. For example, one study analysed the interaction between standardisation organisations and OSS communities through analysis based on 20 case studies and a survey involving stakeholders from standardisation organisations and OSS communities (Blind and Böhm, 2019). Other examples are studies reporting details concerning standardization and other coordination mechanisms in open source software projects (Egyedi and van Wendel de Joode, 2004), organisational influences in and between the W3C RDFa standard and its implementation in the Drupal OSS project (Gamalielsson et al., 2015), challenges for organisations planning software development covering IT standards (Lundell et al., 2019), the relationship between OSS and SEPs (Maracke, 2019), and implementation of ISO standards in OSS (Lundell et al., 2015). This paper extends results earlier reported on influences between ICT standards and their implementations in open source software projects with a specific focus on the H.264 standard (Gamalielsson and Lundell, 2020).

\section{RESEARCH APPROACH}

Overall, the research approach in this study encompasses elite interviews with subsequent open coding that were chosen in order to investigate and account for experiences and insights concerning reasons for and challenges related to engagement with standards and their software implementations (for the first part), and a case study that was chosen in order to provide a systematic and in-depth investigation of organisational engagement and control in the context of ICT standards and their implementation in OSS where quantitative and descriptive analyses are employed (for the second part).

For the first part, where the first, second, third and fourth research questions are addressed, and where we report on experiences and insights concerning reasons for and challenges related to engagement with standards in the multimedia field and implementation of such standards in OSS projects, the two researchers conducted elite interviews with experts with long-term experience from engaging with, using and implementing multimedia standards in OSS projects as respondents. More specifically, the respondents are: one maintainer of an OSS project implementing a multimedia file format; two senior core developers from an OSS project implementing various multimedia file formats; one OSS project maintainer with expertise in implementing open standards in OSS projects and with knowledge about the multimedia field; one IT lawyer with extensive experience from the multimedia field; one senior expert with leading roles who has long experience from multimedia, including broadcasting scenarios; one senior expert in implementing standards in OSS projects with experience from the multimedia field; one senior expert with leading roles and long experience from implementing open standards in OSS-projects and with knowledge about the multimedia field; one senior expert with leading roles and long experience from ICT standardisation and with knowledge about the multimedia field; one senior expert with leading roles in academia and beyond, with a focus on computer science and open source software in fields that include multimedia; and one expert with long experience from long-term maintenance and preservation of files from the multimedia domain. Concerning the scope for the first four research questions, it was clarified to respondents prior to the interview that experiences and insights were sought both from the perspective of an individual (that may or may not be affiliated with an organisation) and the perspective of an organisation. Data collection was based on the results of nine face-to-face interviews (In February 2020) conducted in English and two interviews conducted over email in March 2020. Face-to-face interviews were recorded, transcribed, and vetted by each interviewee. Questions were prepared in advance, and shown to the interviewee before the conduct of the interview. During each interview, follow-up questions were used in the dialogue. Each interview was conducted in an informal setting and allowed each interviewee to extensively elaborate on all issues covered during the interview. A total of 11 interviews were conducted, where recordings for the face-to-face interviews ranged in time from 5 to 21 minutes, and the total transcribed and vetted interview data comprised 65 pages. In this process each 
interviewee was allowed to further elaborate and clarify their responses. The transcribed interview data was analysed within a couple of months after data collection had been completed. An individual analysis was followed by group sessions where researchers discussed and made reflections on each researcher's interpretation. Coding of data from interviews was conducted in a manner which follows ideas on open coding proposed by Glaser (Lings and Lundell, 2005). The unit used for coding was sentences or paragraphs within notes from interviews. Focus was on constant comparison: indicator to indicator, and indicator to emerging concepts and categories (Lings and Lundell, 2005). During the analysis, abstract concepts that are grounded in data from the field, were developed and refined via collected data in the transcriptions. The process of coding resulted in a set of categories, where each category is presented within sub-sections for the four different research questions in the section "Results - experiences and insights" in this paper. To investigate the first four research questions, the elite interviews were supplemented with a literature analysis related to each question.

For the second part, by conduct of a case study involving a systematic investigation of editorship for the H.264 standard, management of ITU-T Study Group 16 for multimedia (hereafter referred to as SG16), and code contributions to the OSS projects OpenH264 and x264 that implement H.264, we analysed organisational engagement and control in the context of ICT standards and their implementation in OSS where quantitative and descriptive analyses are employed. To address the fifth research question (What characterises organisations that engage with and control the H.264 standard?), official and relevant ITU-T web pages for the standardisation of H.264 were analysed in order to identify engagement by different organisations over time. The analysis covers the time window from the first version of H.264 (edition 1, approved 30 May 2003) to the latest version (edition 13, approved 13 June 2019). To address the sixth research question (What characterises organisations that engage with and control OSS projects implementing the H.264 standard?), organisational engagement was analysed in widely deployed OSS projects implementing H.264. Specifically, the OpenH264 (openh264.org, 2020) and x264 (videolan.org, 2020a) projects were chosen. Those projects are amongst the most widely deployed OSS implementations of H.264. Both libraries have over the years been adopted by many applications in need of H.264 encoding and decoding, for example GStreamer, Mozilla Firefox, and OpenWebRTC (for OpenH264); and ffmpeg, Handbrake, and VLC media player (for x264). Further, the ITU-T Telecommunication Standardization Advisory Group (TSAG) has in a proposal exclusively listed OpenH264 and x264 as two "external" OSS projects that are related to the ITU-T reference implementation of H-264 (ITU-T, 2017). In our analysis we specifically focused on the history of binary releases, code contributors and associated organisational affiliation over time. The analysis covers the time window from the first commit in each project (OpenH264: October 2013, x264: June 2004) until 31 January 2020, and data was collected from the projects' official Git code repositories of OpenH2642 and $\times 264^{3}$. Results from the second part of the study are presented in the section "Results - the case of H.264" in this paper.

\section{RESULTS - EXPERIENCES AND INSIGHTS}

This section draws from experiences and rich insights from experts with long-term experience from engaging with, using and implementing multimedia standards in OSS projects. Related to each of the four research questions that are addressed in the subsections, different categories emerged from our analysis that elaborate reasons for and challenges related to engagement with standards in the multimedia field and implementation of such standards in OSS projects. 


\subsection{Reasons Why Individuals and Organisations Get Engaged With Governance and Development Of Standards for Multimedia Formats}

\subsubsection{Benefits for the Own Organisation}

Organisations may get engaged for monetary reasons and the benefit of the own organisation. One respondent expressed that "organizations get involved when they want to make money". Similarly, another respondent stated that organisations engage "because multimedia is usually made to make money". A different respondent perceived that organisations "have already developed some part of a new technology, and they want to make sure that this gets into the standard so they can capitalize on the investment that they have made in developing that". Similarly, it was also stated by a respondent that companies may get involved "to erode standards and to implement them in very narrow way, to benefit the economic prospects of such companies." It was pointed out by another respondent that a standards organisation may provide "documents which are sold, because this is a business model of the standards organization". Related to monetary benefits of engagement with governance and development of standards, one respondent highlighted that use of patents is "basically a money maker for the companies driving the specifications" and that "standards are created by people whose business model is to collect royalties for patents".

\subsubsection{Promotion of Sustainability and Openness of Standards and Standardisation}

Another reason for organisational engagement with governance and development of standards is to promote sustainability and openness of standards and standardisation. According to one respondent, individuals and organisations may get engaged in order "to have an open standard that can be implemented by anyone, that's not encumbered". Similarly, a different respondent stressed that apart from companies, stakeholders that get involved "are atypical participants among the others: they want to provide advanced unencumbered solutions for the benefit of society". Further, a different respondent highlighted the importance of open communication in standardisation and conformance to standards: "I think citizens and individuals get involved because they are concerned that the communication between different parties should be open and should follow the standards". The longterm sustainability perspective of standards is also highlighted by a respondent expressing that that in some organisational contexts it may be of strategic importance to get involved with governance and development of "formats which would be both readable and understandable in the perspective of dozens of years, formats which are well documented and standardized". Related to sustainability of standards, a respondent perceived that a company may get engaged "to spread to a lot of users using their product, their codec".

\subsubsection{Technical Needs and Interest}

There may be technical needs and interests of individuals and organisations that motivate engagement with governance and development of standards. Concerning technical needs, a respondent stated that one reason is "the need to "scratch itches"” and specifically exemplified that they "desperately needed scalable compression for technical P2P related reasons". Another reason can according to another respondent be that organisations may develop media players that "play content and then they obviously need those formats for their media or to store the content in". The need for improving standardisation in the field of multimedia is also highlighted by a respondent "because we see the huge mess". Concerning interest as motivation for engaging with multimedia standardisation, one respondent stressed that individuals involved are often "intrinsically motivated/intellectually challenged by media codecs, containers etc." Similarly, a different respondent stated that "the algorithms about, let's say, image processing or moving image, video or sound, can be a fascinating field".

In summary, results show that reasons why individuals and organisations get engaged with governance and development of standards for multimedia formats include: 
- benefits for the own organisation

- $\quad$ promotion of sustainability and openness of standards and standardisation

- technical needs and interest

\subsection{Reasons Why Individuals and Organisations Get Engaged With Standard Implementations for Multimedia Formats In Open Source Software Projects}

\subsubsection{Technical Needs and Interest}

There may be technical needs and interests of individuals and organisations that motivate engagement with standard implementations of multimedia formats in OSS. Concerning technical needs, there may be a need to incorporate certain features in an OSS project may lead to forking the project, as expressed by one respondent: "I wanted to do things that weren't done ... I wanted to move things a little faster than they were moving in the original project." Further, the same respondent saw a need to improve the performance of the implementation: "The actual implementation was too slow. So I wanted to make things faster, and that's what motivated me to get involved." Further, the respondent also remarked that the implementation provided from the original OSS project "was full of bugs". A different respondent highlighted the need for codecs for a certain operating systems as a reason for engaging with standard implementations, that there is a "routine frustration from using Linux and not having the codecs you need." Concerning interest as motivation, one respondent expressed that "people are very often simply very much interested in doing cool software" and that "multimedia is something which appeals to many people" and that contributors get involved in OSS projects in that context since "they enjoy the community there." Another respondent commented that individuals may choose to engage with OSS projects in the field "because you're a little obsessed with it". The field of multimedia may also be perceived as attractive and easy to relate to be contributors. One respondent stated that those "standards provide a clear and thankful target to work towards, and their visual nature makes them highly rewarding to work on".

\subsubsection{Organisational Needs}

There may also be organisational needs that motivate engagement. A respondent highlighted that "national organizations, like national libraries and archives want to find formats they can store things in." Another respondent stated that an organisation for a specific standard may "need to consume and to produce content encoded in that standard". The sheer amount of content in organisational context may also motivate engagement, as expressed by a respondent: "I imagine they do it because there is a lot of content".

\subsubsection{Promotion of Interoperability, Availability and Long- term Sustainability of Standard Implementations}

Reasons for engaging may also relate to promotion of interoperability, availability and long-term sustainability of standard implementations. To promote interoperability of implementations in the field of multimedia, one respondent explained that for a specific file format "you want to interpret that file format or speak that protocol, since it's a standard protocol, in order to interoperate with other implementations out there". The importance of OSS projects to promote interoperability is highlighted by another respondent: "For free and open source projects, the great benefit of building towards supporting an existing or emerging standard is interoperability and benefitting from the critical mass gathered by it". A specific experience was elaborated by a different respondent who stated that "there was only one active open source implementation" for a specific standard and "I wanted to suggest my fork as another reference implementation." To promote availability of standard implementations, a respondent commented that one reason to get engaged is "to spread the standard, the product, to everyone". Relatedly, one respondent stressed that "if the implementation is open course that means a lot of projects can use it and you can use from Windows, from Mac, from Android, and everyone 
can use it". Further, one respondent mentioned the importance for reasons of long-term sustainability to create "an open source and free codec", and that "this is really how to publish software when your costumer can face licensing and royalty issues".

In summary, results show that reasons why individuals and organisations get engaged with standard implementations for multimedia formats in open source software projects include:

- technical needs and interest

- $\quad$ organisational needs

- promotion of interoperability, availability and long-term sustainability of standard implementations.

\subsection{Challenges for Individuals and Organisations To Get Engaged With Governance and Development of Standards for Multimedia Formats}

\subsubsection{Technical Complexity of Standards}

The technical complexity of standards can be challenging for individuals and organisations seeking to get engaged with governance and development of standards for multimedia formats. In the experience of one respondent, multimedia standards are "deeply technical and participating in drafting and issuing large multimedia standards requires a lot of time and a lot of technical knowledge" and therefore it is for individuals and open source projects "very very hard at times participating in this standard creation". Similarly, a different respondent expressed: "I guess my background and my capabilities weren't really enough to really contribute. Because you need to really understand a lot about codecs and the actual design of codecs". Further, in the view of another respondent, a complicating factor in this context is that "sometimes the technical documents are incomplete in certain aspects and you need to have them amended to make sure that some corner cases are covered".

\subsubsection{Cost of Participation}

A challenge and inhibiting factor related to engagement with governance and development of standards for multimedia formats can, for some prospective contributors, be the cost of participation. This is elaborated by one respondent: "I couldn't afford to travel to Macau for example to go to the latest JPEG meetings". The same respondent also explained that "just to go those meetings can be costly. So that's a barrier, I think". Apart from costs for travelling, the challenge of becoming a member to contribute is highlighted and elaborated by a different respondent: "In order to participate in shaping the standards or even revising or correcting mistakes in the specification, you always need to become a member of the related entity, which typically includes rather high fees, which excludes again pure open source projects, or some people who just do that for fun or in their spare time". Similarly, concerning involvement of individuals and small players and member fees for standardisation organisations, another respondent states that "I'm certainly not going to pay 6000 Euros a year just to fix something in a spec. I mean, that has no benefit to me. It should in the interest of the standards body to incorporate such fixes."

\subsubsection{A Non-inclusive Standardisation Community}

Another challenge for engagement concerns aspects related to a non-inclusive standardisation community. In the experience of one of the respondents, in the field of multimedia, "standards setting organisations are not really a welcoming or open community to engage with". Similarly, concerning multimedia standards, another respondent perceives that "it's a pretty closed process in specifying those". One respondent also expressed that in the field of multimedia standardisation "the barrier to entry for participation is high. So participation is left to traditional actors as well as stakeholders like Intel, Google and others". Similarly, another respondent explained that it can be challenging for SMEs to get involved in standardisation since "stakeholders represented instead are mainly the technology producers, which means companies having a huge portfolio". Concerning governance of 
OSS projects implementing multimedia standards, one respondent commented that big companies involved in standardisation "do tend to publish their software as open source, but often with closed governance". To make standardisation communities in the field of multimedia more inclusive, a respondent stressed that "it's very important for a standards organization to make sure that they are open to everybody and have a low threshold for comments for people to help improve standards."

In summary, results show that key challenges for individuals and organisations to get engaged with governance and development of standards for multimedia formats include:

- technical complexity of standards

- cost of participation

- a non-inclusive standardisation community

\subsection{Challenges for Individuals and Organisations To Get Engaged With Standard Implementations for Multimedia Formats In Open Source Software Projects}

\subsubsection{Technical Complexity of Implemented Standards and Hardware}

The technical complexity of standards can pose different challenges for individuals and organisations seeking to engage with standard implementations for multimedia formats in OSS projects. As expressed by one respondent, in order to implement a standard in software "you have to understand the standard itself". A different respondent elaborated on the competence needed to implement multimedia standards in OSS: "It's very hard to get, enlist people to work on these projects" since "they're so complicated. They require a lot of background". One respondent also highlighted the need to understand hardware aspects for performance reasons: "You have a complex standard, and you have to understand that standard" and "you also have to know the architecture of the hardware to be able to get good performance". For the specific scenario of implementing standards for image compression, one respondent explained that it involves "quite advanced algorithms, you have to have a certain mathematical understanding also to be able to implement".

\subsubsection{Legal Aspects Related to Implementation of Standards}

There are different challenges related to legal aspects that inhibit engagement with OSS projects implementing multimedia formats. One such challenge is patents, which is elaborated by a respondent who states that multimedia "formats are a big, big, software patent minefield" and that "patents are even more aggressively enforced in some countries than others". Similarly, a different respondent stated that "the field is cluttered with many patents". In the view of another respondent, compression techniques are particularly problematic: "it really is a minefield for patents in compression". One respondent also stressed that the concept of patents for standards, "acts as a trade barrier" and that "the unreasonable duration of patents is a major issue for the community". The need for patent licences in order to implement multimedia standards was also mentioned by a respondent: "The real challenges of multimedia standards is that they are designed to require a patent license". The cost of patent licences can be substantial. In the experience of one respondent, for patent licences there can for example be "a minimum annual fee of 100000 , or I don't know what kind of ridiculous amount" and "the annual minimum fees just made it economically completely unfeasible for a small player to legally correctly work in the market". Further, the respondent expressed that use of patents is "anti-competitive, and it distorts the ability and the fair entrance to interoperable systems in markets where such schemes are used."

Implementing standards in the multimedia field that are encumbered with patents in OSS projects poses a number a challenges. One respondent expressed that "if you actually open up, if you actually produce software you could be exposed to people, lawyers coming after you" and "it is a concern, especially with codecs". Similarly, the risk for being subjected to legal actions is highlighted by one respondent who expresses that OSS projects may become "a target of an action by the patent 
holders". The difficulty of commercial use of OSS implementations of encumbered standards is further highlighted by another respondent who states that "the biggest problem is of course software patents on standardized formats or protocols or systems" and use of patents "drastically impedes with the commercial or professional use of an open source implementation of a standard that includes patented technologies."

It was expressed by a respondent that implementation of multimedia standards in OSS is not feasible: "If you want to have a license for the patents, it's not possible to implement these multimedia standards in open source software". More specifically, the use of FRAND (fair, reasonable, and non-discriminatory) conditions for licensing of patents in standards is considered very problematic, especially in context of OSS implementations of multimedia standards, and in the words of one respondent FRAND "is almost a no-go area" and you may "need years for legislation, procurement and other rules", by "which time that technology is often out of date". Similarly, another respondent commented that "this FRAND discussion that is going on here is a nightmare". Related to this, a respondent commented that for open source projects "it's nearly impossible to have a successful ... a commercially successful project by violating the patents". One reason for this, as expressed by a respondent, is that there are organisations "that lock competitors out of the market" and that "people call them patent trolls".

The need for OSS projects to be able to implement standards in the multimedia field without legal issues is elaborated by a respondent who states that concerning multimedia standards, "it is really important that the open source community is allowed to implement these standards without any encumberment". One way to achieve this, in the experience of one respondent, is to use open and royalty free standards as a way to avoid legal issues: "We mostly see patents as a big issue for open source projects" and the codec "AV1 is free to use and shared, and the project was developed trying to avoid the existing patents". Recent developments in the field of digital rights management (DRM) and the impact of this on multimedia formats and their implementations is elaborated by a respondent: "DRM and the commercial interest behind DRM" can "work against providing the content in the open formats". The issue of DRM is also confirmed by another respondent who also stresses that "copyright infringement of source code" is another issue.

\subsubsection{Clarity, Completeness, and Correctness of Standard Specifications}

Challenges related to clarity, completeness and correctness of standard specifications can also affect engagement with standard implementations for multimedia formats in OSS projects. Concerning clarity of specifications, the readability has been raised as an issue. As stated by one respondent, "I think the specifications are always hard to read". This is confirmed by another respondent who expressed that "the standards can be very dry and difficult to read". Issues related to ambiguity and preciseness have also been raised. In the experience of one respondent, for specifications of standards, "there is some ambiguity always". Another respondent commented that "a technical document to describe the standard, it is never precise enough." Concerning clarity of specifications, one respondent perceives a positive trend in that "it's getting better than before. The old specifications are really, really difficult" but there are still "crazy things which are expected to be understood by the implementer".

The completeness of standards is also perceived as challenging. Specifically, one respondent elaborated on that the software implementation may deviate from the standard specification: "Users will always come up with some format that is hard to decide how to deal with. Should be an error? Should that be rejected? So you have to have an approach of how you're going to deal with bending the standard or whether something is not acceptable or not". The need for expertise for interpreting specifications is stressed by a respondent who stated that this "requires expertises as the standard documents are both incomplete and rely on 'interpretation' and belief/consensus that is not documented". The specification of a standard may also contain parts which are incorrect, in the words of one respondent "there might be some things which are simply wrong in the documentation". 
A different related matter highlighted by a respondent is that "specifications can change name, also. Or can split. This is really hard to follow sometimes". Issues related to temporary standards are highlighted by a respondent who explains that concerning specifications of standards, "some are just temporary, and when they are implemented by big players they become de facto a standard" and "if you have a temporary specification, you need to make sure that no one will ever release content based on it".

\subsubsection{Combining Open and Proprietary Standards, Implementations, and Hardware}

It can also be challenging to combine open and proprietary standards, implementations, and hardware in order to engage with standard implementations for multimedia formats in OSS projects. Concerning use of implementations of proprietary container formats in top of open standard formats, one respondent commented that "as core format you might have a good, open standardized format, but then you put a layer on top of it, which actually takes that advantage away". This issue is elaborated, in a somewhat different manner, by another respondent who states that concerning container formats, it is problematic that "people are trying to push content into incompatible formats". The challenge that interfaces for hardware acceleration may be required for reasons of performance with respect to speed and battery consumption and are only accessible through use of closed software is elaborated by one respondent: "Even if you are doing a perfectly working open source implementation of a format, it might not be practical or usable for the users, because it's not fast enough and uses a lot of battery." The issue of accessing hardware functions when implementing multimedia standards in open source is, according to another respondent, complicated by the fact that "sometimes you even have things which are only available in hardware. Some things which are hidden on purpose".

\subsubsection{Access to the Specification of a Standard}

Getting access to the specification of a standard can be a challenge for individuals and organisations seeking engagement with standard implementations for multimedia formats in OSS projects. As stated by one respondent, technical specifications are "usually not accessible to the open source community", and in the context of OSS projects another respondent stresses that "it is really hard when the products and the codec is totally closed, when you can't even have access to specification".

More specifically, the cost for getting access to a specification can be an issue, as commented by one respondent "it's often quite expensive". In the context of OSS projects, the fees for certain multimedia standards may be prohibitive, as elaborated by a different respondent: "you cannot pay when you are working on open source project, you cannot pay for such standards". Similarly, a different respondent explained that "for people doing open source, having to pay 1,000 euros to access the documentation is not an option". The issue of fees in the context of small projects and organisations is raised by a respondent who states that "you need to pay a lot of money just to access a specification through ISO. For big companies it's not an issue, but for small projects it can be really, really annoying". Concerning the cost for access to normative references in a specification, according to a respondent "that also may be expensive". A prohibitive cost for access to the latest version of a specification of a standard may have negative consequences for OSS projects since, according to one of the respondents, a developer that does not have access to the latest version of the specification "might be making errors. Because you don't have the latest, because you don't want to pay". Further, contributors to OSS projects may also have a personal conviction about fees for standard specifications, as commented by a respondent: "I personally don't like at all the model of hiding standards documents behind a paywall”.

The normative references in specifications of standards in the multimedia field may pose a significant challenge, as expressed by one respondent "one of the problems may be that a new standard document refers to various other previous standards and references them, and then some of those old references may disappear or they may change location on where to find them". Further, a different 
respondent highlights issues concerning normative references in specifications and that it can be a challenge to have an "external reference in non-standardized protocols".

Another challenge related to access, according to one respondent, is that a multimedia system "can be a totally opaque system, which is totally impossible to implement as an open source software". The respondent further elaborates that "if you go to the DVD licensing page, or the Blu-ray license agreement, then just to study the software you need to sign an NDA which is telling you that anything you learn from the documents you'll receive is not allowed to be shared in any way", something which means that "the only way to develop software compatible with DVD and Blu-ray is through reverse engineering". This, in the experience of the respondent "directly prevents you to make an open source project." This issue is also elaborated by another respondent who states that "you have to have one people that reads the standard, but it cannot be the same one that code because of some legal [issues]".

\subsubsection{Interoperability of Implementations of a Standard}

Challenges related to achieving interoperability of implementations of a standard can also have affect on engagement. According to one of the respondents, a strategy to promote interoperability of implementations of standards in the multimedia field is for developers contributing to OSS projects that read and write files in multimedia formats to "be permissive what you accept and be strict about what you send out". Another respondent elaborated on the how to promote interoperability in the following way: "If you have multiple implementations of a standard, you want to make sure that all of them follow the standard".

A challenge for OSS projects implementing multimedia standards may also, according to a respondent, be that it may be "very difficult to find access to other implementations to the interoperability testing". Related to this, a different respondent has experienced that in a scenario where equipment manufacturers are involved, it is often the case that "their implementations are used and not an alternative open source implementation that is being created. So they don't have an interest to do interoperability testing." Concerning the impact on interoperability through involvement of dominating vendors, according to another respondent commented that "the main considerations concerning interoperability with other software implementations, is that the large corporate browser vendors are very dominant" and "if Google, Apple or Microsoft do something to the web platform (which they have destabilised through WHAT WG) that affects others very significantly".

Reverse engineering practices in the context of OSS implementing standard specifications in the multimedia field can inhibit interoperability since, in the experience of one respondent, "you can never guarantee your users that it will work completely satisfactorily, because you're only guessing how it works".

\subsubsection{Lack of Support and Contributions From Users and Community}

There are also views that there may be lack of support and contributions to an open source project that implements a standard, that may impact on the engagement with standard implementations for multimedia formats in OSS projects. As expressed by a respondent "you don't get a lot of support from the users, like financial support for example". A respondent also highlighted that lack of external contributions may lead to an unsustainable situation with respect to workload: "You get some type of burnout after a while, if you get a lot of people demanding things" and when they are not "contributing back to the project".

\subsubsection{Deployment of Standard Implementations}

A major challenge may also be to achieve a wide deployment for OSS implementations of standards in the multimedia field in competition with proprietary alternatives with a strong commercial drive. This is elaborated on by one of the respondents: "It's very difficult for an open source codec, no matter how good it be, to succeed against the corporate muscle of people who have a vested interest in making money of the codec". The importance for those who engage with an OSS implementation 
to raise funds for promoting and encouraging its use is highlighted by a respondent who states that "you need people to go and tell people to use it" and that "people cost money, and unless you're getting money, it's hard to tell people about it".

In summary, results show that key challenges for individuals and organisations to get engaged with standard implementations for multimedia formats in open source software projects include:

- technical complexity of implemented standards and hardware

- legal aspects related to implementation of standards

- clarity, completeness and correctness of standard specifications

- combining open and proprietary standards, implementations, and hardware

- $\quad$ access to the specification of a standard

- interoperability of implementations of a standard

- $\quad$ lack of support and contributions from users and community

- deployment of standard implementations

\section{RESULTS - THE CASE OF H.264}

\subsection{Characterisation of Organisations That Engage with and Control The H.264 Standard}

The H.264 standard (ITU-T, 2019) is developed by the ITU-T Video Coding Experts Group (ITU-T, 2020) together with the ISO/IEC JTC1 Moving Picture Experts Group (MPEG, 2020). Further, it is "published as technically-aligned twin text in both organizations ITU-T and ISO/IEC." (ITU-T, 2019). The H.264 standard has evolved from edition 1 (approved 30 May 2003) through 18 revisions (which also include 3 corrigendums and two amendments) to the current edition 13 (approved 13 June 2019).

Table 1 and Table 2 show detailed results related to organisational engagement with and control of the H.264 standard. Specifically, Table 1 shows the organisational engagement with the development of H.264 in terms of organisational affiliations of editors for the standard over the different so called "study periods" (P1=2005-20084, P2=2009-2012, P3=2013-2016, and P4=2017-2020) established by ITU-T. We find that there are eight organisations in total. It can be observed that Microsoft has been represented at editorial level during all study periods, and Apple has been represented during the latest two study periods. Hence, large US-based IT enterprises have a long term engagement with the standard at editorial level. In this study, organisations are categorised into the following types ${ }^{5}$ : Micro Enterprise (MiE, an enterprise with 1-9 employees), Small and Medium-sized Enterprise (SME, an enterprise with 10-250 employees), Larger Enterprise (LE, an enterprise with more than 250 employees), Research Organisation (RO), Higher Education Institution (HEI), Standardisation Organisation (SO), Non-profit Organisation (NPO), Public Sector Organisation (PSO), Public Broadcasting Service (PBS), and Engineering Organisation (EO). Editors for H.264 represent the following organisation types: five LEs, one PBS, and two ROs. Organisations have headquarters located in Asia (two LEs), Europe (one PBS and one RO), and North America (three LEs and one RO).

There was a special team known as the Joint video team (JVT) which was a "group of video coding experts from ITU-T Study Group 16 (VCEG) and ISO/IEC JTC 1 SC 29 / WG 11 (MPEG) created to develop an advanced video coding specification" (ITU-T, 2020b). The contact persons for JVT represented the organisations Fraunhofer HHI, ITU-T, and Microsoft. At a higher organisational abstraction level, the leadership for the Video Coding Experts Group (VCEG) has during the latest two study periods (2013-2016 and 2017-2020) consisted of individuals representing Fraunhofer HHI, Intel, and Microsoft. VCEG did not exist during earlier study periods. At the level of SG16 (which VCEG is part of), there has been a number of individuals representing different organisations during the four study periods, which is visualised in Table 2 . We note that there are 23 organisations in total. ITU-T is the only organisation which has been part of the management group for all four study 
Table 1. Affiliations of editors for H.264 over time $(P 1=2005-2008, P 2=2009-2012, P 3=2013-2016$, and $P 4=2017-$ 2020)

\begin{tabular}{|c|c|c|c|c|c|}
\hline Organisation, HQ location & Type & P1 & $\mathbf{P 2}$ & P3 & P4 \\
\hline Apple, US & LE & & & $\mathrm{X}$ & $\mathrm{X}$ \\
\hline $\mathrm{BBC}, \mathrm{UK}$ & PBS & & & $\mathrm{X}$ & \\
\hline Fraunhofer HHI, Germany & $\mathrm{RO}$ & $\mathrm{X}$ & $\mathrm{X}$ & & \\
\hline Harmonic, US & LE & $\mathrm{X}$ & & & \\
\hline Huawei, China & LE & & & & $\mathrm{X}$ \\
\hline Microsoft, US & LE & $\mathrm{X}$ & $\mathrm{X}$ & $\mathrm{X}$ & $\mathrm{X}$ \\
\hline Mitsubishi Electric Research Laboratories, US & RO & $\mathrm{X}$ & & & \\
\hline NTTGroup, Japan & LE & $\mathrm{X}$ & & & \\
\hline
\end{tabular}

Table 2. Affiliations of management group members for SG16 over time $(P 1=2005-2008, P 2=2009-2012$, $P 3=2013-2016$, and $P 4=2017-2020$ )

\begin{tabular}{|c|c|c|c|c|c|}
\hline Organisation, HQ location & Type & P1 & $\mathbf{P 2}$ & P3 & P4 \\
\hline Cisco Systems, US & LE & & & $\mathrm{X}$ & \\
\hline Council for Scientific and Industrial Research, South Africa & RO & & & $\mathrm{X}$ & \\
\hline Deutsche Telekom, Germany & LE & & $\mathrm{X}$ & $X$ & \\
\hline Ente Nacional De Comunicaciones, Argentina & PSO & & & & $\mathrm{X}$ \\
\hline Federal University of Juiz de Fora, Brazil & HEI & & & & $\mathrm{X}$ \\
\hline France Telecom, France & LE & $\mathrm{X}$ & & & \\
\hline Hankuk University of Foreign Studies, South Korea & HEI & & $\mathrm{X}$ & $X$ & $\mathrm{X}$ \\
\hline Huawei Technologies, China & LE & & $\mathrm{X}$ & $\mathrm{X}$ & $\mathrm{X}$ \\
\hline ITU-T, Switzerland & SO & $\mathrm{X}$ & $\mathrm{X}$ & $\mathrm{X}$ & $\mathrm{X}$ \\
\hline Keio University, Japan & HEI & & & $X$ & \\
\hline $\begin{array}{l}\text { Ministère de la Communication et des Nouvelles Technologies de l'Information, } \\
\text { Guinea }\end{array}$ & PSO & & $\mathrm{X}$ & & \\
\hline $\begin{array}{l}\text { Ministère des Postes et Télécommunications chargé de la ..., Central African } \\
\text { Republic }\end{array}$ & PSO & & & & $\mathrm{X}$ \\
\hline Ministry of Telecommunications, Lebanon & PSO & & & $\mathrm{X}$ & \\
\hline Mitsubishi Electric Corporation, Japan & LE & $\mathrm{X}$ & $\mathrm{X}$ & $X$ & \\
\hline National Centre of State Cadastres, Geodesy, and Cartography, Uzbekistan & PSO & & & $\mathrm{X}$ & \\
\hline National Telecom Regulatory Authority, Egypt & PSO & & & $X$ & $\mathrm{X}$ \\
\hline National Tunisian Broadcasting Office, Tunisia & PBS & & & & $\mathrm{X}$ \\
\hline OFCOM, Switzerland & PSO & $\mathrm{X}$ & & & \\
\hline Oki Electric Industry Co., Ltd., Japan & LE & & & & $\mathrm{X}$ \\
\hline Orange, France & LE & & $\mathrm{X}$ & & \\
\hline Psytechnics, UK & SME & $\mathrm{X}$ & & & \\
\hline Syrian Telecom Establishment, Syrian Arab Republic & LE & & $\mathrm{X}$ & & \\
\hline Waseda University, Japan & HEI & $\mathrm{X}$ & & & \\
\hline
\end{tabular}


periods, which may be unsurprising given that it is the standardisation organisation behind H.264. Three organisations have made a long term commitment by being part of the management group for three out of four study periods ("Hankuk University of Foreign Studies", "Huawei Technologies", and "Mitsubishi Electric Corporation"). The management group has a diversified set of organisations, both in terms of organisation type and location of headquarters. Specifically, management group members represent different organisation types: four HEIs, eight LEs, one PBS, seven PSOs, one RO, one SME, and one SO. Organisation headquarters are located in Africa (one PBS, three PSOs, and one RO), Asia (three HEIs, four LEs, and two PSOs), Europe (three LEs, one PSO, one SME, and one SO), North America (one LE), and South America (one HEI and one PSO).

\subsection{Characterisation of Organisations That Engage with and Control OSS Projects Implementing the H.264 Standard}

Since OpenH264 was provided as OSS by Cisco in October 2013, there have been 11 binary releases of OpenH264, from v1.0.0 (May 2014) through v2.0.0 (June 2019). Code contributions have been made to the code repository for OpenH264 since October 2013. It should also be pointed out that proprietary software development has been conducted before the point when OpenH264 was provided as OSS and that it therefore is unknown when the initial development of the software begun.

From the study of official webpages, there have been approximately 30 binary releases for x 264 for different operating systems from July 2013 through December 2019. It should be noted that code contributions have been made to the code repository for x264 since June 2004, so the option of compiling from source code might have been available at a stage earlier than the date for the first binary release.

Table 3 and Table 4 show detailed results related to organisational engagement with and control of OSS projects implementing the H.264 standard. Specifically, Table 3 shows affiliations and number of author code contributions to the OpenH264 OSS project over the four study periods of the H.264 standard. We note that there are 17 organisations in total. It is evident that the overwhelming majority of contributions have been made by Cisco Systems, which may be unsurprising since that organisation released and maintain the OpenH264 OSS project. Further, the total number of author code contributions for the two study periods P3 and P4 is 5011 of which 3178 stem from the organisations in Table 3. Hence, a minority (1833, representing 37\%) of the contributions stem from individuals who (given the used email address in the Git repository) are not affiliated with an organisation when contributing. In Table 3, a minority of the organisations have only provided a single contribution (7 out of 17). Code contributors to OpenH264 represent a diversified set of organisations, both in terms of organisation type and location of headquarters (see Table 3). Specifically, contributors represent: seven LEs, four MiEs, one NPO, and five SMEs. Organisation headquarters are located in Asia (two LEs), Europe (one LE, two MiEs, and four SMEs), and North America (four LEs, two MiEs, one NPO, and one SME).

Table 4 shows number of commits for author code contributions to the x264 OSS project over the four study periods of the H.264 standard. We note that there are 24 organisations in total. It is evident that the overwhelming majority of contributions have been made by VideoLAN and X264 LLC. The total number of author code contributions for the four study periods (P1-P4) is 2911 of which 1497 stem from the organisations in Table 4. Hence, approximately half of the code contributions stem from individuals who (given the used email address in the Git repository) are not affiliated with an organisation when contributing. In Table 4, the majority of the organisations have only provided a single contribution (15 out of 24). Code contributors to x264 represent a diversified set of organisations, both in terms of organisation type and location of headquarters (see Table 3). Specifically, contributors represent: one EO, five HEIs, three LEs, eight MiEs, two NPOs, one PBS, and four SMEs. Organisation headquarters are located in Europe (one EO, two HEIs, one LE, five MiEs, one NPO, one PBS, and two SMEs), North America (three HEIs, two LEs, three MiEs, one NPO, and one SME), and Oceania (one SME). 
Table 3. Affiliations and number of author code contributions to the OpenH264 project over time $(P 1=2005-2008$, $P 2=2009-2012, P 3=2013-2016$, and $P 4=2017-2020$ )

\begin{tabular}{|l|l|l|l|l|l|c|}
\hline \multicolumn{1}{|c|}{ Affiliation, HQ location } & Type & P1 & P2 & P3 & P4 & Total \\
\hline Belledonne Communications, France & SME & - & - & 3 & 0 & 3 \\
\hline Centricular Ltd, UK & SME & - & - & 2 & 9 & 11 \\
\hline Cisco Systems, US & LE & - & - & 2734 & 342 & 3076 \\
\hline Comcast Corporation, US & LE & - & - & 0 & 4 & 4 \\
\hline Gentoo Foundation, Inc., US & NPO & - & - & 1 & 0 & 1 \\
\hline Google LLC, US & LE & - & - & 0 & 5 & 5 \\
\hline Highfive, US & SME & - & - & 0 & 1 & 1 \\
\hline Igalia S.L., Spain & SME & - & - & 0 & 4 & 4 \\
\hline Kodak Alaris Inc., US/UK & LE & - & - & 3 & 0 & 3 \\
\hline Loongson Technology Co., Ltd., China & LE & - & - & 0 & 11 & 11 \\
\hline Mozilla Corporation, US & LE & - & - & 10 & 0 & 10 \\
\hline Netfarm, Italy & SME & - & - & 0 & 1 & 1 \\
\hline NetVision Ltd., Israel & LE & - & - & 1 & 0 & 1 \\
\hline Remotium, Inc., US & MiE & - & - & 1 & 0 & 1 \\
\hline RTFM, Inc., US & MiE & - & - & 33 & 0 & 33 \\
\hline The Staaker Company AS, Norway & MiE & - & - & 1 & 0 & 1 \\
\hline Thincast Technologies GmbH, Austria & MiE & - & 0 & 1 & 1 \\
\hline
\end{tabular}

\section{ANALYSIS}

\subsection{Contrasting Projects for Standardisation and Implementation of H.264}

From the results, differences concerning mix of organisation types and location of headquarters can be observed for standardisation of H.264 when considering all four ITU-T study periods for the standard. We find that LEs from North America and Asia dominate the editorship of the standard and that organisations of two other types (PBS and RO) contribute, whereas the management group for SG16 is, in comparison, more organisationally diversified (containing organisation types HEI, LE, PBS, PSO, RO, SME, and SO) than the editorship group and is not dominated by any single type of organisation. In terms of headquarter location, it can be observed that organisations contributing to editorship of H.264 are located in three continents (Asia, Europe, and North America), and that organisations in the management group for SG16 are located in five continents (Africa, Asia, Europe, North America, and South America). Hence, there is an observed geographical diversity for the editorship of H.264, and to an even larger extent for the management group of the standard.

From the results, differences concerning mix of organisation types and location of headquarters can be observed for implementation of H.264 in the two OSS projects OpenH264 and x264 when considering all four study periods for the standard. We find that one LE from North America (Cisco Systems) is clearly dominating in terms of number of code contributions to the OpenH264 project and that there are organisations, apart from LEs, of three other types (MiE, NPO, SME). For the x264 project, one NPO from Europe (VideoLAN) and one MiE from North America (X264 LLC) are clearly dominating in terms of number of code contributions and that there are organisations, apart from the NPO and MiE, of five other types (EO, HEI, LE, PBS, and SME). Hence, the study finds that the $\mathrm{x} 264$ project is more organisationally diversified in comparison to OpenH264, even if there 
Table 4. Affiliations and number of author code contributions to the $x 264$ project over time $(P 1=2005-2008$, $P 2=2009-2012, P 3=2013-2016$, and $P 4=2017-2020$ )

\begin{tabular}{|c|c|c|c|c|c|c|}
\hline Affiliation, HQ location & Type & P1 & $\mathbf{P 2}$ & P3 & $\mathbf{P 4}$ & Total \\
\hline Agile Generation AB, Sweden & SME & 0 & 1 & 0 & 0 & 1 \\
\hline Antcom, Germany & $\mathrm{MiE}$ & 0 & 0 & 1 & 0 & 1 \\
\hline $\mathrm{BBC}, \mathrm{UK}$ & PBS & 0 & 0 & 1 & 0 & 1 \\
\hline Bluebottle, Australia & SME & 0 & 3 & 0 & 0 & 1 \\
\hline Centricular, Ltd., UK & $\mathrm{MiE}$ & 0 & 0 & 1 & 0 & 1 \\
\hline Collabora Ltd, UK & SME & 0 & 1 & 0 & 0 & 1 \\
\hline Gentoo Foundation, Inc., US & NPO & 0 & 1 & 4 & 13 & 18 \\
\hline Google LLC, US & LE & 0 & 1 & 0 & 0 & 1 \\
\hline Imagination Technologies Group plc, UK & LE & 0 & 0 & 9 & 1 & 10 \\
\hline iThink Software, US & $\mathrm{MiE}$ & 4 & 7 & 0 & 0 & 11 \\
\hline Joost, US & $\mathrm{MiE}$ & 6 & 0 & 0 & 0 & 6 \\
\hline Lavabit LLC, US & $\mathrm{MiE}$ & 0 & 1 & 0 & 0 & 1 \\
\hline Linaro, Ltd., UK & EO & 0 & 1 & 0 & 0 & 1 \\
\hline Luleå University of Technology, Sweden & HEI & 0 & 42 & 0 & 0 & 42 \\
\hline North Dakota State University, US & HEI & 0 & 0 & 1 & 0 & 1 \\
\hline Oberlin College, US & HEI & 1 & 0 & 0 & 0 & 1 \\
\hline Open Broadcast Systems Ltd, UK & MiE & 0 & 1 & 2 & 2 & 5 \\
\hline Red Hat, Inc., US & LE & 0 & 0 & 1 & 0 & 1 \\
\hline Remlab Tmi, Finland & $\mathrm{MiE}$ & 0 & 1 & 0 & 0 & 1 \\
\hline Rensselaer Polytechnic Institute, US & HEI & 2 & 1 & 0 & 0 & 3 \\
\hline Universität Hamburg, Germany & HEI & 1 & 0 & 0 & 0 & 1 \\
\hline VGo Communications Inc., US & SME & 0 & 0 & 1 & 0 & 1 \\
\hline VideoLAN, France & NPO & 628 & 0 & 0 & 0 & 628 \\
\hline X264 LLC, US & MiE & 152 & 550 & 49 & 0 & 751 \\
\hline
\end{tabular}

are few code contributions from organisations other than the dominating organisations in each of the two OSS projects. In terms of headquarter location, we note that organisations contributing code to the OpenH264 project are located in three continents (Asia, Europe, and North America) and that organisations contributing code to the $\mathrm{x} 264$ project are located in three continents (Europe, North America, and Oceania). Hence, there is an observed similar geographical diversity for organisational code contributions to OpenH264 and x264.

When comparing the diversity of organisations contributing to editorship of H.264 and management of SG16 with the diversity of organisations contributing code to the OSS projects OpenH264 and x264, the following can be observed when considering all four ITU-T study periods for the standard. Both the editorship of H.264 and code contributions to the OpenH264 OSS project are dominated by LEs, whereas code contributions to the x264 OSS project are dominated by a NPO and a MiE. The $\mathrm{x} 264$ project exhibits a greater diversity in terms of organisation types compared to the editorship for H.264, whereas, in comparison, the OpenH264 project and the editorship of H.264 have a similar (and lower) organisation type diversity. Further, the management group for SG-16 
and the $\mathrm{x} 264$ project have a similar (and high) organisation type diversity. In terms of headquarter location, editorship for H.264 and both the studied OSS projects implementing the standard have a similar geographical diversity (all having contributors from three continents). Further, the management group for SG-16 exhibits a greater geographical diversity (having contributors from five continents) than both OSS projects.

\subsection{Findings in Relation to Organisational Strategies for the Case of H.264}

For the organisations that engage with and control the H.264 standard, we focused on and investigated strategic statements from organisations that have contributed to the editorship for $\mathbf{H . 2 6 4}$ through analysis of annual reports for each year of the study periods each organisation was contributing. This was done to investigate whether there are explicit statements regarding strategic involvement in ICT standardisation, and possibly in H.264 specifically. In addition to an overarching consideration of strategic statements from large organisations, the analysis considered corporate summaries and specific statements through a search for relevant keywords. The outcome of the analysis is as follows.

Apple states in all their annual reports that the company provides products for streaming of video (including high definition video), and for that purpose use of standards (including H.264) is required.

In the 2012-13 annual report BBC mentions that they provide live high definition video streaming of different types of events and video on demand services. Further, in the 2013-14 annual report, further development of an online video $\&$ audio player and means for delivering interactive video are pointed out as prioritised activities. BBC mentions in the 2014-15 annual report that they have collaborated with many organisations for developing industry technologies and standards, and in the 2016-17 annual report it is mentioned that research costs cover "longer-term research of new technology and standards that benefit the whole industry". Further, provision of online video streaming and video on demand is highlighted as increasingly important in the 2016-17 annual report, and BBC increased its presence and introduced video streaming on social media platforms (including Facebook). Overall, all these activities and efforts undertaken by BBC require use of video standards such as H-264.

Fraunhofer HHI is deeply involved in multimedia standardisation and in the 2004-05 annual report it is stated that "One of the main activities in 2004 was the consolidation of the video coding standard H.264/AVC and the establishing of this standard in committees". Specifically, activities in SG16 and JVT are highlighted amongst a number of other standardisation committee activities. It is also mentioned that the organisation develops its own software and hardware implementations of H.264/AVC. A large number of communication and dissemination activities related to H.264/AVC are highlighted in the 2006-07 annual report, which indicates a strategic commitment to the standard. Engagement in committee activities related to H.264/AVC was intensified during this period. For the period 2008-09 the annual report points out the highly successful deployment of H.264/AVC and highlights the EMMY award that went to the JVT of which Fraunhofer HHI is a member that has made significant contributions. The success and strategic importance of contributing to H.264/AVC was further amplified in the 2010-12 annual report, where a number of other awards for contributions to the standard were highlighted.

Harmonic states in their 2005 and 2006 annual reports that the current research and development efforts are focused heavily on new video compression standards, which includes H.264. Specifically, the company is "developing products, including HD encoders, based on these new standards in order to remain competitive". Further, the company points out in their 2007 and 2008 annual reports that compliance with new video standards (including H.264) is of strategic value in that "these widely adopted standards enables interoperability with products manufactured by other companies".

Huawei states in their 2017 annual report that they develop "video-based production systems for a key group of domains, such as public safety, where video is the primary vehicle of digital transformation" and a strategy of the company is "to enable digital transformation with ICT infrastructure and intelligent devices." Video standards (including H.264) and associated software implementations are necessary to realise this strategy. Further, development and provision of video 
based solutions is seen as core to the company in light of the large and rapidly increasing number of mobile video users (approximately 1.4 billion at the time). In addition, in the 2018 annual report the company states that it aims to "help carriers the world over accelerate their development of video services".

Microsoft reports on different patent and intellectual property claim processes related to video patents in four (2008-2011) annual reports, which indicates that video standards are of strategic importance to the company. Further, in the 2012-15 annual reports, Microsoft points out several court cases specifically related to violation of standard essential patents filed for H.264 when the standard is implemented in software.

According to their 2005 annual report, the NTTGroup contributed to realising video distribution services and announced the development of an interactive video communication service featuring ultra-high-definition video technology, something which indicates the strategic importance of video standards (including H.264) and associated software implementations. Further, the NTTGroup states that they will "contribute to the standardization of technologies, including the development of industry standards, and will actively move forward with research and development activities carried out in collaboration with other research institutions". In the 2006 annual report the NTTgroup points out that they are "a leading developer of new services, such as high-quality, easy-to-use interactive video communication services", aim to "enhance and broaden its lineup in video communication services", and has also developed technology for video conferences. In the annual report from 2007 it is also mentioned that they do research and development to provide "secure, safe, and convenient broadband and ubiquitous communications services" that involve video technologies.

Annual reports were also analysed during study of the OSS project OpenH264 where we chose to focus on Cisco Systems, which has provided an overwhelming majority of the contributions to the project. Using the same keywords as for the analysis of organisations that have contributed to editorship for H.264 (with the addition of the keyword "open source"), we analysed annual reports for all study periods, with the assumption that Cisco Systems has performed substantial proprietary software development to implement H.264 prior to the third and fourth study period during which OpenH264 was released and maintained as an OSS project. The outcome of the analysis is as follows. In the annual report from 2005, the company states that it "provides a broad line of products for transporting data, voice, and video" and that "we sell scalable, standards-based networking products", which indicates that ICT standards (including video standards such as H.264) are of strategic importance to the company. Further, in 2006 the company pointed out that they address the growing demand for networked video and for that reason acquired a provider of set-top boxes, end-to-end video distribution networks, and video system integration, to further strengthen their business. In 2007, the company acquired another provider of network-delivered entertainment and interactive media (including video). The company stated in 2008 that customers have begun to "understand firsthand the power they can gain by implementing video and visual networking solutions". Further, the company reported increased sales of video systems in the same year. In 2009, one explicit business objective for the company was "readying all of our products and solutions for the escalating use of video" and it was also stated that "providing products and solutions to enable more robust video delivery is key to Cisco's differentiation". The same year, another acquisition of a provider of video solutions was made. In 2010 the company states that video is "increasingly becoming the most important means by which we communicate", and in the 2011-14 annual reports, video is considered one the company's foundational priorities. Further, conformance to standards is stated as one principal competitive factor for the company in the 2011-19 annual reports. In 2012 the company acquired a leading provider of video software to strengthen its business offering. The company announced OpenAppID in 2014, which is an OSS licensed application detection solution, which indicates their strategic interest in the OSS development model, and in 2015-16 annual reports the company stated that utilisation of the OSS computing platform OpenStack is part of their cloud strategy. The same year the company introduced several products that support the H.265 standard (the successor of H.264). In 2016 the 
company acquired a provider to enhance its collaboration strategy to deliver video across both cloud and hybrid environments. Further, in 2016 and 2018-19 the company completed a divestiture of two parts of the company with a focus on video solutions (the Service Provider Customer Premises Equipment business and the Service Provider Video Software Solutions business), which may indicate a strategic choice to focus less on video in future business offerings. In 2019 the company highlighted standards bodies as one stakeholder group important to engage with for long-term value creation.

For the OSS project x264, the organisation VideoLAN that, together with X264 LLC, has provided the overwhelming majority of code contributions by organisations is a NPO, and therefore no annual reports are available. However, it has been stated that "VideoLAN produces free software for multimedia" and that the organisation is "composed of a team of volunteers who believe in the power of open source to rock the multimedia world" (videolan.org, 2020b). Hence, it is unsurprising that the $\mathrm{x} 264$ OSS project has been strongly influcenced by VideoLAN. It should also be mentioned that no annual reports are available for X264 LLC.

\subsection{Findings in Relation to Previous Research for the Case of H.264}

Previous research has presented and elaborated three different scenarios for standard development (Lundell and Gamalielsson, 2017), which have also been adopted for categorisation of research results in a study on the relationship between OSS and standard setting (Blind and Böhm, 2019). Overall, in the first scenario, development of a standard in the context of a formal or informal standardisation organisation precedes its implementations in software; in the second scenario, a software implementation precedes development and recognition of technical specifications of a standard by formal or informal standardisation organisations; in the third scenario, there is "reciprocal action between development of technical specifications of a standard together in parallel with development of one (or several) implementation(s) of technical specifications of a standard in software" (Lundell and Gamalielsson, 2017). In the case of H.264, we note that the development of the standard and its associated technical specification has since the first edition that was approved in October 2003 been further developed continuously until (and beyond) its latest release in June 2019. Concerning the OSS implementation OpenH264, its initial code contributions and first release happened long after the first edition of the H.264 standard was approved. However, due to the proprietary development prior to the establishment of the OSS project OpenH264, it is unknown when software development started. For x264, its first code contributions were made approximately one year after the first edition of H.264 and the first binary release was much later (July 2013). The current edition of the ITU-T reference implementation (ITU-T, 2016) was released in December 2016 and the two earlier editions of this software were released in February 2016 and October 2014, respectively. These findings altogether, and the lack of overlap between organisations participating in the governance and management of H.264 and organisations contributing code to the OpenH264 and x 264 projects, suggest that the first scenario of standard development applies for H.264. It is also evident that both OSS projects have been developed concurrently with the development of different editions of the H.264 standard (but without the reciprocal action between standardisation and implementation).

It may be considered unsurprising that only LEs, and not SMEs, are involved in editorship of H.264 or management of SG16. This may indicate that the observed lack of interest amongst SMEs is in-line with previous research which shows that there are considerable barriers for entry for smaller organisations wishing to contribute to development of standards in the context of traditional standardisation organisations (Krechmer, 2006). Further, the identified domination of LEs based in the US and Asia that contribute to the editorship of H.264 is similar to the overall domination of US-based LEs and organisations observed in editorship in W3C standardisation (Gamalielsson and Lundell, 2017b).

One of the principal motivations for companies to engage with formal standardisation is to satisfy the interest of the company (Blind and Mangelsdorf, 2016). Hence, if the development of a specific ICT standard is dominated by a limited number of influential (and often large) companies 
this may lead to incorporation of features in the specification that are important to those companies only. Strategic engagement with standardisation organisations and use of standards and standardsbased technologies can be considered an important part for any organisation aiming to develop and implement an OSS strategy, as elaborated by legal corporate counsels at Cisco Systems and Oracle Corporation (Cohn and Spiegel, 2011).

\section{CONCLUSION AND DISCUSSION}

The first part of the study contributes experiences and rich insights concerning reasons for and challenges related to engagement with standards in the multimedia field and implementation of such standards in OSS projects. In summary, findings from the first part of the study show the following. Reasons why individuals and organisations get engaged with governance and development of standards for multimedia formats include: benefits for the own organisation; promotion of sustainability and openness of standards and standardisation; and technical needs and interest. Reasons why individuals and organisations get engaged with standard implementations for multimedia formats in open source software projects include: technical needs and interest; organisational needs; and promotion of interoperability, availability and long-term sustainability of standard implementations. Challenges for individuals and organisations to get engaged with governance and development of standards for multimedia formats include: technical complexity of standards; cost of participation; and $\boldsymbol{a}$ non-inclusive standardisation community. Challenges for individuals and organisations to get engaged with standard implementations for multimedia formats in open source software projects include: technical complexity of implemented standards and hardware; legal aspects related to implementation of standards; clarity, completeness and correctness of standard specifications; combining open and proprietary standards, implementations, and hardware; access to the specification of a standard; interoperability of implementations of a standard; lack of support and contributions from users and community; and deployment of standard implementations.

The second part of the study contributes a rich characterisation of organisations that engage with and control the H.264 standard, and organisations that engage with and control the OSS projects OpenH264 and x264 implementing the H.264 standard. Further, the investigated projects for standardisation and implementation of H.264 are contrasted with respect to mix of contributing organisations, and findings are related to organisational strategies of organisations contributing to the editorship of H.264 and previous research. In summary, findings from the second part of the study show that LEs from North America and Asia dominate the editorship of the H.264 standard and that participating organisations have headquarters in Asia, Europe, and North America. Further, one LE from North America dominates the OpenH264 OSS project, and one NPO from Europe together with one MiE from North America dominate the x 264 OSS project. The study finds that the $\mathrm{x} 264$ project is more organisationally diversified in comparison to OpenH264, and there is a similar geographical diversity for organisational code contributions to OpenH264 and x264. Overall, findings in relation to organisational strategies show that organisations contributing to the editorship of H.264 and implementation of OpenH264 may: develop and provide products, hardware, software and services that require use of video standards (including H.264); strategically engage with standardisation organisations, projects, and activities; and strategically engage with open source projects for adoption and deployment in the context of business critical ICT solutions.

Several of the findings in the first part of the study concerning reasons for and challenges related to engagement with standards in the multimedia field and implementation of such standards in OSS projects, confirm findings in other studies that are from other studies and contexts. For example, concerning identified reasons to engage with governance and development of standards for multimedia formats, "benefits for the own organisation" and "technical needs and interest" are in-line with motivations "enforce own content" and "solve company specific technical problem" reported in Blind and Mangelsdorf (2016). Another example concerns challenges to get engaged with standard 
implementations for multimedia formats in open source software projects, there are several findings that are in agreement with challenges that have been identified in the context of implementation of the document format PDF in OSS (Gamalielsson and Lundell, 2013). For example, the challenges "legal aspects related to implementation of standards", "clarity, completeness and correctness of standard specifications" are in-line with challenges identified in the context of the PDF document format (Gamalielsson and Lundell, 2013). Hence, findings from the first part in this study may apply and be transferred beyond the multimedia context, and provide a detailed elaboration on new and specific experiences and rich insights in order to enrich the body of knowledge in the field of ICT standardisation.

Findings from the case of H.264 in the second part show that development of this standard in the context of a formal or informal standardisation organisation precedes its implementations in software. However, it should be emphasised that that reference implementations, such as the ITU-T reference implementation for H.264, have an important role and contribute to the evolution of the standard it implements and helps other stakeholders that implement a standard in software provided under both open source software licenses and proprietary conditions to validate the different standard features. Further, the role of the software implementation can be different in other standardisation contexts (e.g. ETSI). One example of an effort where standardisation has promoted utilisation of OSS in their work is the ETSI-hosted Open Source MANO project ${ }^{6}$ that develops an Open Source NFV Management and Orchestration (MANO) software stack that is aligned with ETSI NFV. This Apache 2.0-licensed OSS project has provided different types of feedback to formulate and finalise the ETSI MANO standards. Hence, different standardisation contexts can learn from and utilise new and specific experiences concerning the role of software implementations in other contexts in order to improve standardisation processes in a rapidly changing world.

\section{ACKNOWLEDGMENT}

This research has been financially supported by the Swedish Knowledge Foundation (KK-stiftelsen) and participating partner organisations in the LIM-IT project. The authors are grateful for the stimulating collaboration and support from colleagues and partner organisations. 


\section{REFERENCES}

Bain, M. (2012). Scene Setting - Licensing models for standards and for open source. EC Workshop: Implementing FRAND standards in Open Source: mission impossible? Brussels, Belgium.

Behlendorf, B. (2009). How Open Source Can Still Save the World. In 5th IFIP WG 2.13 International Conference on Open Source Systems (OSS 2009), Skövde, Sweden. doi:10.1007/978-3-642-02032-2_2

Bird, G. B. (1998). The Business Benefit of Standards. StandardsView, 6(2), 76-80. doi:10.1145/301688.301691

Bitmovin. (2019). Video Developer Report 2019. Bitmovin. https://go.bitmovin.com/video-developer-report-2019

Blind, K. (2006). Explanatory factors for participation in formal standardisation processes: Empirical evidence at firm level. Economics of Innovation and New Technology, 15(2), 157-170. doi:10.1080/10438590500143970

Blind, K., \& Böhm, M. (2019). The Relationship Between Open Source Software and Standard Setting. Publications Office of the European Union.

Blind, K., \& Mangelsdorf, A. (2016). Motives to standardize: Empirical evidence from Germany. Technovation, 48-49, 13-24. doi:10.1016/j.technovation.2016.01.001

Brock, A. (2013). Understanding Commercial Agreements With Open Source Companies. In S. Coughlan (Ed.), Thoughts on Open Innovation - Essays on Open Innovation from leading thinkers in the field. OpenForum Europe LTD for OpenForum Academy.

Butler, S., Gamalielsson, J., Lundell, B., Brax, C., Mattsson, A., Gustavsson, T., Feist, J., \& Lönroth, E. (2020). Maintaining Interoperability in Open Source Software: A Case Study of the Apache PDFBox Project. Journal of Systems and Software, 159, 159. doi:10.1016/j.jss.2019.110452

Cohn, A. G., \& Spiegel, G. (2011). Effective Open Source Development Business Practices. The Computer \& Internet Lawyer, 28(1), 1-17.

Crowston, K., \& Howison, J. (2006). Assessing the Health of Open Source Communities. Computer, 39(5), 89-91. doi:10.1109/MC.2006.152

de Vries, H. J. (2006). IT Standards Typology. In K. Jakobs (Ed.), Advanced Topics in Information Technology Standards and Standardization Research (Vol. 1, pp. 1-26). Idea Group Publishing.

Egyedi, T. M. (2007). Standard-compliant, but incompatible?! Computer Standards \& Interfaces, 29(6), 605-613. doi:10.1016/j.csi.2007.04.001

Egyedi, T. M., \& Dahanayake, A. (2003). Difficulties implementing standards. In Proceedings of the 3rd Conference on Standardization and Innovation in Information Technology (pp. 75-84). doi:10.1109/ SIIT.2003.1251197

Egyedi, T. M., \& van Wendel de Joode, R. (2004). Standardization and Other Coordination Mechanisms in Open Source Software. International Journal of IT Standards and Standardization Research, 2(2), 1-17. doi:10.4018/ jitsr.2004070101

Engelfriet, A. (2010). Choosing an Open Source License. IEEE Software, 27(1), 48-49. doi:10.1109/MS.2010.5

EU. (2004). European Interoperability Framework for pan-European eGovernment Services. Version 1.0, European Commission.

EU. (2012). Guidelines for Public Procurement of ICT Goods and Services: SMART 2011/0044, D2 - Overview of Procurement Practices. Final Report, Europe Economics.

Fitzgerald, A., \& Pappalardo, K. (2009). Moving Towards Open Standards. SCRIPTed, 6(2), 467-483.

Fitzgerald, B. (2006). The transformation of Open Source Software. Management Information Systems Quarterly, 30(4), 587-598. doi:10.2307/25148740

FRAND. (2012). Implementing FRAND standards in Open Source: Business as usual or mission impossible? EC Workshop, Report of FRAND and OS event, Brussels, Belgium. 
Friedrich, J. (2011). Making innovation happen: The role of standards and openness in an innovation-friendly ecosystem. In Proceedings of the 7th International Conference on Standardization and Innovation in Information Technology (pp. 1-8). doi:10.1109/SIIT.2011.6083609

Friedrich, J. (2013). Getting Requirements Right: Towards a nuanced approach on standardisation and IPRs. In S. Coughlan (Ed.), Thoughts on Open Innovation - Essays on Open Innovation from leading thinkers in the field. OpenForum Europe LTD for OpenForum Academy.

FSF. (2020). The Free Software Foundation. https://www.fsf.org/

Gamalielsson, J., \& Lundell, B. (2013). Experiences from implementing PDF in open source: challenges and opportunities for standardisation processes. In K. Jakobs (Ed.) Proceedings of the 8th IEEE Conference on Standardization and Innovation in Information Technology (pp. 39-49). IEEE. doi:10.1109/SIIT.2013.6774572

Gamalielsson, J., \& Lundell, B. (2017a). On licensing and other conditions for contributing to widely used open source projects: an exploratory analysis. In Proceedings of the 13th International Symposium on Open Collaboration. ACM. doi:10.1145/3125433.3125456

Gamalielsson, J., \& Lundell, B. (2017b). On organisational involvement and collaboration in W3C standards through editorship. Journal of Internet Services and Applications, 8(5), 5. doi:10.1186/s13174-017-0056-1

Gamalielsson, J., \& Lundell, B. (2020). On influences between ICT standards and their implementations in open source software projects: The case of H.264. In K. Jakobs (Ed.), The Past, 20/20 and FUTURE of ICT Standardisation, Book of papers of the 11th International Conference on Standardisation and Innovation in Information Technology. Mainz Publishers.

Gamalielsson, J., Lundell, B., Feist, J., Gustavsson, T., \& Landqvist, F. (2015). On organisational influences in software standards and their open source implementations. Information and Software Technology, 67, 30-43. doi:10.1016/j.infsof.2015.06.006

Ghosh, R. A. (2005). Open Standards and Interoperability Report: An Economic Basis for Open Standards. FLOSSPOLS Deliverable, D4, 12.

Isaak, J. (2006). The Role of Individuals and Social Capital in POSIX Standardization. International Journal of IT Standards and Standardization Research, 4(1), 1-23. doi:10.4018/jitsr.2006010101

ITU-T. (2016). H.264.2: Reference software for ITU-T H.264 advanced video coding. https://www.itu.int/rec/TREC-H.264.2-201602-I/en

ITU-T. (2017). Open Source and Reference Implementation. Proposal, TSAG-C.4. https://www.itu.int/md/ T17-TSAG-C-0004/en

ITU-T. (2019). H.264: Advanced video coding for generic audiovisual services. https://www.itu.int/rec/T-RECH.264-201906-I

ITU-T. (2020). Video Coding Experts Group (VCEG). https://www.itu.int/en/ITU-T/studygroups/2017-2020/16/ Pages/video/vceg.aspx

ITU-T. (2020b). Joint video team. https://www.itu.int/en/ITU-T/studygroups/com16/video/Pages/jvt.aspx

ITU-T. (2020c). ITU-T Rec. H.264 declared patent(s). https://www.itu.int/ITU-T/recommendations/related_ ps.aspx?id_prod=6312

Krechmer, K. (2002). Cathedrals, Libraries and Bazaars. In Proceedings of the 2002 ACM Symposium on Applied Computing (pp. 1053-1057). doi:10.1145/508791.508997

Krechmer, K. (2005). The Meaning of Open Standards. In Proceedings of the 38th Hawaii International Conference on System Sciences. IEEE Computer Society. doi:10.1109/HICSS.2005.605

Krechmer, K. (2006). Open Standards Requirements. International Journal of IT Standards and Standardization Research, 4(1).

Krechmer, K. (2007). Event report - The Open Standards International Symposium. Journal of IT Standards \& Standardization Research, 5(2), 59-62. 
Lings, B., \& Lundell, B. (2005). On the adaptation of Grounded Theory procedures: Insights from the evolution of the $2 G$ method. Information Technology \& People, 18(3), 196-211. doi:10.1108/09593840510615842

Lundell, B., \& Gamalielsson, J. (2017). On the potential for improved standardisation through use of open source work practices in different standardisation organisations: How can open source-projects contribute to development of IT-standards? In K. Blind \& K. Jakobs (Eds.), Digitalisation: Challenge and Opportunity for Standardisation. Proceedings of the 22nd EURAS Annual Standardisation Conference (vol. 12, pp. 137-155). EURAS Contributions to Standardisation Research, Verlag Mainz.

Lundell, B., Gamalielsson, J., \& Katz, A. (2015). On implementation of Open Standards in software: To what extent can ISO standards be implemented in open source software? International Journal of Standardization Research, 13(1), 47-73. doi:10.4018/IJSR.2015010103

Lundell, B., Gamalielsson, J., \& Katz, A. (2019). Implementing IT Standards in Software: Challenges and recommendations for organisations planning software development covering IT standards. European Journal of Law and Technology, 10(2).

Lundell, B., Gamalielsson, J., \& Mattsson, A. (2011). Exploring Tool Support for Long-term Maintenance of Digital Assets: a Case Study. In V. Fomin, \& K. Jakobs (Eds.), Proceedings: 16th EURAS Annual Standardization Conference (pp. 207-217). European Academy of Standardisation, The EURAS Board.

Lundell, B., \& van der Linden, F. (2013). Open Source Software as Open Innovation: Experiences from the Medical Domain. In J. S. Z. Eriksson Lundström, M. Wiberg, S. Hrastinski, M. Edenius, \& P. J. Ågerfalk (Eds.), Managing open innovation technologies (pp. 3-16). Springer. doi:10.1007/978-3-642-31650-0_1

Mangelsdorf, A. (2009). Driving Factors of Service Companies to Participate in Formal Standardization Processes: An Empirical Analysis. SSRN Electronic Journal, 10.2139/ssrn.1469512

Maracke, C. (2019). Free and Open Source Software and FRAND-based patent licenses. The Journal of World Intellectual Property, 22(3-4), 78-102. doi:10.1111/jwip.12114

Mozilla. (2013). Video Interoperability on the Web Gets a Boost From Cisco's H.264 Codec. https://blog.mozilla. org/blog/2013/10/30/video-interoperability-on-the-web-gets-a-boost-from-ciscos-h-264-codec/

MPEGLA. (2019). AVC/H.264 - Patent List. MPEG LA. https://www.mpegla.com/wp-content/uploads/avc-att1. pdf

openh264.org. (2020). OpenH264. https://www.openh264.org/

OSI. (2020a). The Open Source Initiative. https://opensource.org/

OSI. (2020b). The Open Source Definition. https://opensource.org/osd

Riillo, C. A. (2013). Profiles and Motivations of Standardization Players. International Journal of IT Standards and Standardization Research, 11(2), 17-33.

Rosen, L. (2004). Open Source Licensing: Software Freedom and Intellectual Property Law. Prentice Hall.

Simcoe, T. S. (2006). Open Standards and intellectual property rights. In H. Chesbrough, W. Vanhaverbeke \& J. West (Eds.), Open Innovation researching a new paradigm. Oxford University Press.

SVT. (2020). SVT Play: Teknisk information. https://kontakt.svt.se/guide/teknisk-information

UK. (2015). Open Standards Principles: For software interoperability, data and document formats in government IT specifications. HM Government. https://www.gov.uk/government/uploads/system/uploads/attachment_data/ file/459075/OpenStandardsPrinciples2015.pdf

videolan.org. (2020a). x264. https://www.videolan.org/developers/x264.html

videolan.org. (2020b). VideoLAN. https://www.videolan.org/videolan/

Wakke, P., Blind, K., \& Ramel, F. (2016). The impact of participation within formal standardization on firm performance. Journal of Productivity Analysis, 45, 317-330. 


\section{ENDNOTES}

1 In the context of ISO this standard is referred to as "Information technology - Coding of audio-visual objects — Part 10: Advanced Video Coding" (ISO/IEC 14496-10).

https://github.com/cisco/openh264

https://code.videolan.org/videolan/x264/

$4 \quad$ We acknowledge that there is a gap in time between the approval of the first edition of H.264 (30 May 2003) and the start of the first ITU-T study period.

5 A similar set of categories was used in Gamalielsson and Lundell (2017b).

6 https://osm.etsi.org/ 


\section{APPENDIX A - LIST OF ACRONYMS}

AGPL - (GNU) Affero General Public License

AVC - Advanced Video Coding

BSD (license) - Berkeley Software Distribution (BSD) license

DRM - Digital Rights Management

EO - Engineering Organisation

FRAND - Fair, Reasonable, And Non-Discriminatory

GPL - (GNU) General Public License

HEI - Higher Education Institution

HHI - (Fraunhofer) Heinrich Hertz Institute

ICT - Information and Communications Technology

IEC - International Electrotechnical Commission

ISO - International Organization for Standardization

ITU-T - the International Telecommunication Union - Telecommunication Standardization Sector

JTC - Joint Technical Committee

JVT - Joint Video Team

LE - Larger Enterprise (an enterprise with more than 250 employees)

LGPL - (GNU) Lesser General Public License

MiE - Micro Enterprise (an enterprise with 1-9 employees)

MIT (license) - Massachusetts Institute of Technology (MIT) license

NPO - Non-Profit Organisation

OSI - Open Source Initiative

OSS - Open Source Software

PBS - Public Broadcasting Service

PSO - Public Sector Organisation

RDFa - Resource Description Framework in Attributes

RO - Research Organisation

SG - Study Group

SO - Standardisation Organisation

SEP - Standard Essential Patent

SME - Small and Medium-sized Enterprise (an enterprise with 10-250 employees)

TSAG - (The ITU-T) Telecommunication Standardization Advisory Group

VCEG - Video Coding Experts Group

W3C - World Wide Web Consortium

WG - Working Group

Jonas Gamalielsson is a researcher at the University of Skövde, Sweden. has worked with software development in industry from 1990 to 2001, and has thereafter (since 2001) been involved in teaching and research at the University of Skövde. He received his Ph.D. in computer science from Heriot-Watt University (Edinburgh) in 2009. $\mathrm{He}$ is a member of the Software Systems Research Group at University of Skövde and has conducted research related to open source software in a number of national and international projects since 2008. Focus has been on challenges related to lock-in, interoperability and long-term maintenance of software systems in various contexts. His research is reported in publications in a variety of international journals and conferences.

Björn Lundell received a PhD from the University of Exeter in 2001. He is a professor at the University of Skövde where he leads the Software Systems Research Group, and has been a staff member and researcher since 1984. Professor Lundell's research contributes to theory and practice in the software systems domain and centres on different aspects of openness (in particular open source and open standards) related to development, use, and procurement of software systems. His research addresses fundamental socio-technical challenges concerning software systems, and focuses on different aspects of lock-in, interoperability, and longevity of systems. His research is reported in over 100 papers in a variety of international journals and conferences. Professor Lundell has been active in a number of international and national research projects which have lead to significant scientific and societal impact, and has been an expert advisor and contributed to guidelines and policies in the field. 